\title{
Языкознание
}

\author{
УДК 811.511 .131
}

Л. М. Ивщин

О РУКОПИСИ «МАТЕРІАЛЫ ДЛЯ СРАВНИТЕЛЬНАГО СЛОВАРЯ...»

В данной статье представлены результаты анализа рукописного словаря, хранящегося в одном из архивов г. Кирова. Актуальность исследования обусловлена тем, что для разработки вопросов истории языка (возникновения и развития письменности) в научный оборот необходимо вводить материалы рукописных и опубликованных письменных памятников как важнейших источников, которые показывают картину развития языка на определенном этапе его развития. Рукописный словарь содержит довольно большой список коми-пермяцкой и удмуртской лексики, причем по удмуртскому языку - отдельно по бесермянскому и глазовскому диалектам. В словарь включены лексемы самого различного характера: названия сельскохозяйственных орудий, жилищных построек, домашних животных, зверей, птиц, цветов, деревьев, частей человеческого тела; слова, характеризующие человека и его действия, родственные отношения. Автором рукописи предположительно является статистик Вятского края конца ХІХ века П. М. Сорокин, который составлял подворные описи ряда уездов Вятской губернии и одновременно собирал этнографический и лингвистический материал. В рукописном словаре из 1642 русских слов 1336 переведены на коми-пермяцкий язык, 1037 - на глазовский диалект и 810 - на бесермянское наречие удмуртского языка. Из графико-орфографических особенностей словаря выделяются такие, как: 1) обозначение анлаутного йӧ- буквой ъ; 2) маркировка удмуртских аффрикат при помощи одной буквы или диграфов; 3 ) передача удмуртского диалектного заднерядного звука $b$ (варианта $b l$ ) различными гласными буквами русского алфавита. Другая важная особенность рукописного словаря - использование синонимовдиалектизмов как одного из элементов стилистического обогащения языка.

Ключевые слова: удмуртский язык, коми-пермяцкий язык, глазовский диалект, бесермянское наречие, письменный памятник удмуртского языка, оригинал, рукописный словарь, перевод, удмуртская графика, русская графика, лексика.

DOI: 10.35634/2224-9443-2020-14-2-184-190

В последнее время возобновился интерес исследователей к изучению истории языка, проблем возникновения и развития письменности и литературного языка. Разработка этих вопросов, как известно, требует широкого вовлечения в научный оборот рукописных и опубликованных памятников, которые для многих языков, в том числе удмуртского, - одни из важнейших источников, воссоздающих более или менее полную картину развития языка на определенном этапе его развития. Поэтому актуальность нашего исследования, посвященного анализу языкового своеобразия удмуртского материала рукописного словаря, очевидна. По меткому выражению Д. С. Лихачева, вся история развития человеческой культуры есть история не только созидания новых, но и обнаружения старых культурных ценностей [Лихачев 1987, 649].

В 2019 г. во время работы в архиве Кировской области нами была обнаружена довольно интересная рукопись под названием «Матеріалы для сравнительнаго словаря зюздинскаго пермяцкаго и глазовскаго вотскаго наръчій и бесерменскаго говора» [Материалы]. Автор и время составления словаря не отмечены.

Цель нашей работы - рассмотреть некоторые графико-орфографические и диалектные особенности глазовской лексики словаря.

Копия рукописи с аналогичным названием, снятая в 1960 г. Т. И. Тепляшиной, хранится в научном архиве Удмуртского института истории, языка и литературы УдмФИЦ УрО РАН (РФ, Оп. 2-Н, д. 626). Хотя, казалось бы, письменный памятник содержит солидный лингвистический (в первую очередь, лексический) материал по нескольким языкам - коми-пермяцкому и удмуртскому (включая отдельно по бесермянскому и глазовскому диалектам удмуртского языка), исследователи до настоящего времени не заинтересовались отраженной в нем удмуртской лексикой, во всяком случае данными по глазовскому диалекту. 
Более или менее подробное описание словаря, в особенности материалов по бесермянскому диалекту, содержится в монографии Т. И. Тепляшиной «Язык бесермян» [Тепляшина 1970], назвавшей предполагаемого автора рукописи - статистика Вятского края конца XIX в. П. М. Сорокина, «который имел возможность бывать во многих селениях бывшей Вятской губернии и собирать этнографический и лингвистический материал среди “инородцев”» (цит. по: [Тепляшина 1970, 50]) во время составления подворных описей удмуртов Глазовского, Сарапульского и Слободского уездов Вятской губернии - в 1890-1893 гг. Авторство словаря установлено ею сличением нескольких рукописей: отмечены объем рукописи, примерное количество встречающихся в памятнике слов по каждому языку и диалекту, выделены некоторые диалектные явления по бесермянскому материалу: 1) появление билабиального вставного $w$ между двумя гласными, 2) деаффрикатизация согласного ч в конце слова, 3) смягчение согласных в соседстве с гласными э и $u$ и т. д. Также отмечен тот факт, что Петр Сорокин включил в рукопись свыше 800 бесермянских лексем [Тепляшина 1970, 51-54].

Из других источников узнаем [Голубев 1895,4$]$, что в 1890 году в «Вятских губернских ведомостях» были напечатаны такие лингвистические работы П. М. Сорокина, как «Пословицы вотяков», «Старинный словарь» и «Зюздинский словарь» и некоторые другие [Чураков 2014, 155]. Таким образом рассматриваемая нами рукопись вне сомнения может принадлежать краеведу, историку, этнографу и лингвисту П. М. Сорокину. А если так, то время создания «Матеріалов ...» можно соотнести с периодом составления автором подворных описей ряда уездов Вятской губернии [Чураков 2014, 156] - началом 90-х гг. ХІХ столетия, еще точнее - 1893-1894 гг.

Кроме вышеназванной монографии Т. И. Тепляшиной, некоторые попутные замечания по рассматриваемой рукописи можно встретить еще в нескольких публикациях.

Так, в одной из статей исследователя коми-пермяцкого языка находим следующее: «неизвестный собиратель материалов «для сравнительного словаря зюздинского, пермяцкого и глазовского вотского наречия и бесермянского говора» Вятской губернии приводит в значении «петух» зюздинское слово $m и$, но, скорее всего, здесь допущена ошибка. Возможно, собиратель услышал и записал слово, определяющее молодого петушка или цыпленка - тип» (цитируется по: [Голева 2014, 61]).

В работе известного исследователя бесермянской культуры Е. В. Поповой отмечается, что в словаре «слова приведены в отдельных колонках с их вариантами на разных языках и в русском переводе. Понятий, связанных с культурой питания немного, но словарь фиксирует блюда, бытовавшие в конце 19 столетия с их местными обозначениями» [Попова 2014, 41].

Относительно лексики коми языка, которая отражена в рукописи, хотелось привести некоторые соображения коллеги С. А. Сажиной, старшего научного сотрудника Института языка, литературы, истории Федерального исследовательского центра Коми научного центра УрО РАН: «В передаче зюздинских слов наблюдается много искажений (кортны 'искать', ползебны 'испугать'), в качестве соответствий русским лексемам зачастую приводятся описательные конструкции, к примеру, челядабы 'бездетный', йанзынабы 'бессовестный', остэднэмъ 'беспутный'. В ряде случаев даны неточные соответствия, вероятно, по причине неправильного понимания опрашиваемым русского слова: к примеру, к слову 'колос' приводится соответствие со значением 'колокол' - джыньянъ, 'лазать' нюлны 'лизать', 'молить' - начкыны 'убить', 'огорчить' - курзядны 'сделать горьким', 'втиснуть' шузьдны 'скиснуть'. В то же время в словаре отражена исконная лексика, которая современными носителями верхнекамского наречия уже утрачена: 1) названия деревьев: кычъ 'береза, коз 'ель', лопу 'ольха'; 2) названия птиц: сизь 'дятел', тури 'журавль', джоджёгъ 'гусь', дозмаръ 'тетерев'. Есть ряд слов, которые непонятны, не обнаруживают параллелей в других коми диалектах: джибала 'издавна', вута 'лягушка'».

\section{Общие сведения}

Словарь написан черными чернилами красивым разборчивым почерком на 32 листах бумаги размером 22 на 30 см. Листы заполнены с обеих сторон. Слова располагаются на листах в четыре колонки (столбца). В первом столбце даны коми-пермяцкие слова, во втором - удмуртские, в третьем бесермянские, в последнем - русские. В русском столбце приведено 1642 слова, коми-пермском 1336, удмуртском - 1037, бесермянском - 810 слов. В словарь включены лексемы самого различного характера: названия сельскохозяйственных орудий, жилищных построек, домашних животных, зве-

\footnotetext{
${ }^{1}$ Данные сведения получены нами в ходе устной беседы с коми исследователем.
} 
рей, птиц, цветов, деревьев, частей человеческого тела; слова, характеризующие человека и его действия, родственные отношения и др.

\section{Графические особенности удмуртских слов}

Каждое слово написано с прописной буквы, на некоторых поставлено ударение. Автору словаря были известны, по-видимому, различные говоры удмуртского языка, о чем свидетельствуют сокращения, приведенные автором, например: глз. - глазовский говор, млм. - малмыжский говор, сарп. или capan. - сарапульский говор, слб. - слободской говор. При некоторых удмуртских словах имеются также грамматические пометки, например, лаблуизъ (пр. вр.) [прошедшее время] 'ослабъть' (18).

Для написания удмуртских слов применена русская графика. Ниже рассмотрим подробнее особенности передачи удмуртских букв автором средствами кириллической графики.

1. Буква ь использована для обозначения в удмуртских словах анлаутного йӧ: Ђбэкъ 'лягушка' (12 об.) $)^{2}$, Блъ 'молоко' (13 об.).

2. И десятеричное (i) встречается в одном слове: niосъ муртъ 'мужчина' (13 об.) и обозначает не просто фонему -и-, а инлаутное звукосочетание -ий-.

3. Удмуртские аффрикаты передаются следующим образом:

а) ч применена для обозначения глухой палатальной (ч) и велярной (ӥ): мунчо 'баня' (1), учьконо 'глядеть' (4 об.), чуня 'жеребенокъ' (7); чочъ 'вмъсть' (3 об.), чужоно 'вымести' (4), чонъ 'дымъ' (6 об.), чатча 'льсь' (12 об.). В одном слове аффриката $\ddot{u}$ передается буквосочетанием чш: мучшъ 'кочка' (10 об.);

б) буквосочетание дз и буква з (в нескольких словах) обозначает аффрикату ӟ: адзено 'видъть' (3), дзедзя 'ворота' (3 об.), дзечь 'добрый' (6), сялзыны 'плевать' (19 об.);

в) буквосочетание дж обозначает велярный звонкий согласный ӝ: джотъ 'вечеръ' (3), джуй 'мохъ’ (13 об.), джогявыль 'нескоро' (15 об.).

4. Звук $\ddot{o}$ в абсолютном большинстве слов обозначен буквой ы: быксины 'блеять', ысконо 'блевать', тыль ярси ‘блондин' (1 об.), кытъ ‘брюхо' (2), кый ‘жирь' (7).

5. Буква ы в материалах П. М. Сорокина встречается в не очень большом количестве слов: $\partial о-$ рысъ носъ, матысъ носъ 'ближніе', узы́ръ 'богатый' (1 об.), чикынъ 'давеча' (5 об.), кекы 'колыбель изъ береста' (10), бубы 'отець' (18 об.) и др. Нередко на месте этой буквы находим о или ё: тодё 'бълый’, конё ‘бълка' (2 об.), сёдъ 'вороной’ (3 об.), крес-аё 'вопріемникъ’ (4), иеёръ 'голова' (5), дзичё 'лисица' (12) и др. В подобных словах буквой о (ё) обозначен заднерядный вариант фонемы $b l(b)$, который отмечается исследователями в глазовском диалекте вместо обычного литературного bl [Baxрушев 1959, 229; Карпова 2013, 23; Лыткин, Тепляшина 1959, 218-219]. В некоторых словах звук $b l$ (ъ) передается буквой а: пэймадъ 'впотьмахъ' (4), аргонъ 'мъдь', вала́нъ 'наверху' (14). В небольшом количестве лексем в обозначен буквой э или е: висенъ 'больть' (2), татэнъ 'здъсь' (8).

6. В нескольких словах встречается апостроф: г’нъ сапегъ 'валенки' (2 об.), седк'ръ 'дятель' (6 об.), к’мъ 'корка' (10 об.). Подобным образом, по словам Т. И. Тепляшиной, автором обозначен редуцированный гласный в безударном положении [Тепляшина 1970a, 53], с чем мы в целом согласны.

\section{Диалектные особенности}

1. В начале слова перед гласным $a$ в некоторых словах употребляется неслоговое $\check{y}$ (на месте удмуртского литературного в): уамылшто 'перешагнуть' (19 об.), уатонъ 'погребенье' (20), уаллянъ 'прежній' (21 об.), уазь 'рано' (23). Данное явление, как отмечают ученые, встречается в среднечепецком диалекте [Карпова 2013, 33-34], в части верхнечепецких говоров [Карпова 2016, 23], в нижнечепецких говорах и в бесермянском наречии [Тепляшина 1970а, 160-161; Тепляшина 1970, 119], также в закамских говорах [Kel'makov 1996, 212-213; Насибуллин 1973, 40-41] удмуртского языка. Инициальный неслоговой $\check{y}$ - в сочетании $\check{y} a$ - исследователи возводят к прапермскому *u- [Uotila 1933, 63-70], который в диалектах удмуртского и коми языков претерпел изменения и развился в различные звуки, сохранившись в северных диалектах, отдельных периферийно-южных говорах и бесермянском наречии.

\footnotetext{
2 Здесь и далее ссылка на источник приводится лишь с указанием на страницу, орфография оригинала полностью сохранена.
} 
2. В позиции между инициальным $\kappa$ и последующим гласным $a$ или $u$ в нескольких словах отмечен согласный 8 : квака́ 'ворона' (3 об.), квинь, кюинь 'три' (31 об.). Этот диалектный факт также в свое время был отмечен лингвистами в северноудмуртских говорах [Вахрушев 1959, 231; Тепляшина 1970a, 163].

Употребление ква- / кви- при наличии инициального ўа- является характерным для косинского говора нижнечепецкого диалекта удмуртского языка [Карпова 2016, 20]. По данным современных исследователей, это диалектное явление, по-видимому, имеет более широкое распространение: исследователями оно зафиксировано в верхнечепецких говорах, например, в дебесских [Карпова 2015, 52; 2016, 23, 30], а также в северной части шарканского говора [Максимов 2018, 198-200].

\section{Лексические особенности словаря}

В рассматриваемом словаре нашла отражение лексика различного содержания: названия предметов, орудий труда, орудий действий, способов, разных приемов, относящихся к основным видам хозяйства, явлениям природы и т. д. Т. И. Тепляшина, анализируя рукописную работу П. М. Сорокина [Тепляшина 1970, 55], приводит лишь ряд лексем, характерных для бесермянского наречия: бабача́ 'двоюродный братъ' (5 об.), палтулысь 'полумъсяцъ' (20 об.), атьяно́ 'расхвалить' (23 об.), коссинь 'родимець (припадокь)' (24), біэ́м 'свекровь' (25), наяно́ 'смотреть' (26 об.) и др. Исследователь отмечает, что данный письменный памятник имеет большое значение для определения места бесермянского диалекта в системе северноудмуртских говоров.

Кроме того, в сравнительном словаре зафиксирована лексика, характерная для северноудмуртских говоров, например: нюня 'старшій братъ' (2), кыкъчочэ́нъ 'вдвоемъ' (2 об.), вичакъ 'весь' (3), чикынъ 'давеча', дзезя 'ворота' (3 об.), (5 об.), пискалтоно 'доить' (6), юлтошь 'другъ' (6), окмэ 'достаточно' (6), аскы 'завтра' (7 об.), шора 'индъйка' (8 об.), пэшкля 'кусть' (11 об.), яль 'пень' (19), крезь 'пъсня' (22), юберъ 'скворецъ' (25 об.), каль 'теперь' (28 об.), но́маръ 'червь' (31).

В рукописной работе П. М. Сорокина встречаются также слова, которые не употребительны в современном удмуртском языке или выступают в ином значении: тысьсемъ 'жито', нумыръ 'жукъ' (7), бобо-бубыли 'мотылекъ' (13 об.), пачькэсъ гозь́ 'плетенка', лемтэй 'пльшь' (20), синву 'потъ' (21), азьмуртъ 'толмачь' (29), вумуртъ 'черть' (31). В частности, синву, переведенное автором словаря как «потъ», в современных северных диалектах и удмуртском языке означает «слеза, слезы».

\section{Другие особенности}

1. В материалах словаря чаще всего в пределах одной словарной статьи приводятся синонимы (в некоторых случаях с указанием на диалект): дорысъ носъ, матысъ носъ 'ближніе' (1 об.), инмаръ, куа́зь 'Богъ' (1 об.), чурка, подэмъ 'борть' (2), седк'ръ, сизь 'дятелъ' (6 об.), мужо, кекы сарп., зубка 'колыбель изъ береста' (10), чашшамурть, тэдимурть 'льшій' (12 об.), аргонъ, туй 'мъдь' (14), куа сарп., куала глз. 'шалашъ (чумъ)' (31), ворса глз. и млм., пытса сарп. 'отворяй (ворота)' (18), ай, нюня, бубы 'отець' (18 об.), изяно глз., калны сарп. 'спать' (27), иоркадъ, сюлэгъ 'тъсный' (29 об.). Использование лексической вариативности (разнодиалектных вариантов) в качестве стилистического обогащения языка является одним из основных критериев составления современных словарей.

2. Глаголы в рукописном словаре представлены в безличной форме - с окончаниями -оно/-ёно, но переводятся инфинитивом, например, вертано пиналь 'няньчить' (16), кесяно 'обдирать' (16 об.), боттоно́ 'окончить' (17 об.), кельтоно́ 'оставлять' (18). По мнению Т. И. Тепляшиной, в приведенных словах гласные буквы суффиксов обозначают заднерядный вариант фонемы $b$ (b) [Тепляшина 1970: 53]. С этим трудно согласиться, поскольку удмурты в разговорной речи очень редко использовали неопределенную форму глаголов. Например, в ранее опубликованных словарях или рукописных памятниках глаголы в основном приводятся в форме 1 лица единственного числа: верасько̀ 'сказываю, говорю', лобаско̀ 'летаю' [Сочиненія 1775, 98]; пилискоे 'разщепляюся', юкискоे 'раздъляю, отдъляю, удъляю' [Кротовъ 1785, 169, 279], недыско̀ 'грязну', жуасько̀ 'горю' [Словарь 1820, 2, 11]. В форме инфинитива на -нbl в памятниках обычно дается первое слово составной глагольной или именной конструкции, например: вераны̀ куикыско̀ 'говорить съ къмъ начинаю', вузаны пуктемь́нъ 'на продажу выставленный' [Кротовъ 1785, 23, 33] и др. Эти размышления наводят на мысли о том, что в удмуртском языке, наряду с инфинитивом на -нbl, возможно рассматривать и другие финитные формы глагола. Но это уже тема совершенно другого исследования. 
В данной статье мы эскизно рассмотрели некоторые языковые особенности рукописного словаря П. М. Сорокина, составленного в конце XIX в. Несмотря на небольшой объем памятника, удмуртский материал, содержащийся в нем, представляет определенную ценность для изучения истории удмуртского языка.

\section{СПИСОК СОКРАЩЕНИЙ}

глз. - глазовский диалект удмуртского языка, млм. - малмыжский диалект удмуртского языка, сарп. сарапульский диалект удмуртского языка.

\section{ЛИТЕРАТУРА}

Вахрушев В. М. Об особенностях говоров северного диалекта удмуртского языка // Записки / Удмуртский НИИ ист., экон., лит. и языка при Сов. Мин. Удм. АССР. Ижевск: Удм. кн. изд-во, 1959. Вып. 19. С. $228-238$.

Голева Т. Г. Петух и курица в традиционной культуре коми-пермяков // Вестник ПГГПУ. Серия Гуманитарные и общественные науки. № 3. 2014. С. 60-74.

Голубев П. А. Сорокин П. М. (некролог) // Вятский край. 1895. № 86. С. 4. (21.09.1895).

Карпова Л. Л. Лексика северного наречия удмуртского языка: Среднечепецкий диалект. Ижевск, 2013. $600 \mathrm{c}$.

Карпова Л. Л. Дебесские говоры в системе удмуртских говоров Верхней Чепцы // Вестник Удмуртского университета. Сер. История и филология. 2015. Вып. 5. С. 48-56.

Карпова Л. Л. Некоторые особенности фонетической синтагматики в нижнечепецком диалекте удмуртского языка // Ежегодник финно-угорских исследований. 2016. Вып. 2. С. 17-36.

Кротовъ 1785 - Удмуртско-русский словарь / РАН. УрО. Удмуртский институт истории, языка и литературы. - Ижевск, 1995. (= Краткой Вотской словарь съ россійскимъ переводомъ собранный и по Алфавиту расположенный села Еловскаго Троицкой церкви священникомъ Захаріею Кротовымъ, 1785 года). XX + 208 с. (Памятники культуры Удмуртии: Лингвистическое наследие: Памятники удмуртской филологии I).

Лихачев Д. С. Избранные работы: В 3 т. Т. 1: О себе. Развитие русской литературы; Поэтика древнерусской литературы. Монографии. Л., 1987.

Лыткин В.И., Тепляшина Т. И. Некоторые особенности глазовского диалекта // Записки / Удмуртский НИИ ист., экон., лит. и языка при Сов. Мин. Удм. АССР. Ижевск: Удм. кн. изд-во, 1959. Вып. 19. С. $218-227$.

Максимов С. А. Северноудмуртско-коми ареальные языковые параллели: лексика, фонетика, морфология. Ижевск, 2018. 336 с.

Материалы - Матеріалы для сравнительнаго словаря зюздинскаго пермяцкаго и глазовскаго вотскаго нарьчій и бесерменскаго говора. Центральный государственный архив Кировской области (ЦГАКО). Ф. 170. Оп. 1. Д. 140. 32 л.

Попова E. В. «Лакомые охотники до блинов... народная кухня бесермян в источниках и публикация XIX - первой половины ХХ столетий» // Вестн. Удм. ун-та. Сер. История и филология. 2014. Вып. 3. С. 36-45.

Словарь 1820 - Словарь языка вотского. Научный архив УИИЯЛ УдмФИЦ УрО РАН. Ф. РФ. ОП. 2-Н. Д.

Сочиненія 1775 - Сочиненія принадлежащія къ грамматикъ вотскаго языка. Въ Санктпетербургъ при Императорской Академїи наукъ 1775 года. 113 с. [В кн. Первая научная грамматика удмуртского языка / Удм. НИИ ист., экон., лит. и языка при Сов. Мин. Удм. АССР. Ижевск: Удмуртия, 1975. - С. 3-15 + 113 + 17].

Тепляшина Т. И. Язык бесермян // АН СССР. Ин-т языкозн. М.: Наука, 1970. 288 с.

Тепляшина Т. И. Нижнечепецкие говоры северноудмуртского наречия // Записки / Удмуртский НИИ ист., экон., лит. и языка при Сов. Мин. Удм. АССР. Ижевск, 1970а. Вып. 21: Филология. С. 156-196.

Чураков В. В. Пётр Матвеевич Сорокин - исследователь родовой организации удмуртов // Иднакар. 2014. № 2 (18). C. 153-162.

Kel'makov V. K. Der bilabiale Sonant in den udmurtischen Dialekten // Lapponica et Uralica: 100 Jahre finnischugrischer Unterricht an der Universität Uppsala: Vorträge am Jubiläumsymposium 20.-23 April 1994. Uppsala, 1996. S. 211-224.

Uotila T. E. Zur Geschichte des Konsonantismus in den permischen Sprachen. Helsinki, 1933. XVIII + $446 \mathrm{~S}$.

Поступила в редакцию 18.03.2020

Ившин Леонид Михайлович кандидат филологических наук, научный сотрудник, Удмуртский институт истории, языка и литературы УдмФИЦ УрО РАН 426004, Россия, г. Ижевск, ул. Ломоносова, 4 E-mail: ivleo.75@mail.ru 


\title{
L. M. Ivshin
}

\section{ABOUT THE MANUSCRIPT “MATERIALS FOR A COMPARATIVE DICTIONARY ...”}

\author{
DOI: $10.35634 / 2224-9443-2020-14-2-184-190$
}

This article presents the results of the analysis of a handwritten dictionary stored in one of the archives of Kirov. The relevance of the study is due to the fact that for the development of issues of the history of the language (the emergence and development of writing) it is necessary to introduce materials from handwritten and published written monuments into scientific circulation as the most important sources that show a picture of the development of the language at a certain stage of its development. The manuscript dictionary contains a rather large list of Komi-Permyak and Udmurt vocabulary, moreover, in the Udmurt language, separately in Besermyan and Glazov dialects. The dictionary includes lexemes of the most diverse nature: the names of agricultural implements, housing, pets, animals, birds, flowers, trees, parts of the human body; words characterizing a person and his actions, kinship. The author of the manuscript is supposedly the statistics of the Vyatka Territory at the end of the 19th century P.M. Sorokin, who compiled the courtyard descriptions of a number of counties of the Vyatka province and at the same time collected ethnographic and linguistic material. In a handwritten dictionary of 1642 Russian words, 1336 are translated into the Komi-Permyak language, 1037 into the Glazov dialect, and 810 into the Besermyan dialect of the Udmurt language. From the graphicorthographic features of the dictionary, the following are distinguished: 1) the designation of the annoying $\check{u} \ddot{o}$ - by $\mathrm{b}$; 2) marking of Udmurt affricates with a single letter or digraphs; 3 ) transmission of the Udmurt dialect rear-row sound $b$ (variant $b l$ ) by various vowels of the Russian alphabet. Another important feature of the handwritten dictionary is the use of synonyms-dialectisms as one of the elements of the stylistic enrichment of the language.

Keywords: Udmurt language, Komi-Permyak language, Glazov dialect, Besermyan dialect, written monument of the Udmurt language, original, handwritten dictionary, translation, Udmurt graphics, Russian graphics, vocabulary

Citation: Yearbook of Finno-Ugric Studies, 2020, vol. 14, issue 2, pp. 184-190. In Russian.

\section{REFERENCES}

Vakhrushev V. M. Ob osobennostyah govorov severnogo dialekta udmurtskogo yazyka [On the peculiarities of dialects of the northern dialect of the Udmurt language] // Zapiski / Udmurtskij NII ist., ekon., lit. i yazyka pri Sov. Min. Udm. ASSR. Izhevsk, Udm. kn. izd-vo Publ., 1959, vol. 19. Pp. 228-238. In Russian.

Goleva T. G. Petuh i kurica v tradicionnoj kul'ture komi-permyakov [Rooster and chicken in the traditional culture of Perm Komi] // Vestnik PGGPU. Seriya Gumanitarnye i obshchestvennye nauki [Bulletin of Perm State Humanitarian Pedagogical University. Humanities and social sciences], 2014, vol. 3, pp. 60-74. In Russian.

Golubev P. A. Sorokin P. M. (nekrolog) [Sorokin P.M. (obituary)] // Vyatskij kraj [Vyatka region], 1895 , vol. 86, P. 4. (21.09.1895). In Russian.

Karpova L. L. Leksika severnogo narechiya udmurtskogo yazyka: Srednechepeckij dialect [Vocabulary of the northern dialect of the Udmurt language: Central Cheptsa dialect]. Izhevsk, 2013. 600 p. In Russian.

Karpova L. L. Debesskie govory v sisteme udmurtskih govorov Verhnej Chepcy [Debesian dialects in the Udmurt dialect system of Upper Cheptsa] // Vestnik Udmurtskogo universiteta. Istoriya i filologiya. [Bulletin of Udmurt University. History and Philology]. 2015. Vol. 5. Pp. 48-56. In Russian.

Karpova L. L. Nekotorye osobennosti foneticheskoj sintagmatiki v nizhnechepeckom dialekte udmurtskogo yazyka [Some features of phonetic syntagmatics in the Lower Cheptsa dialect of the Udmurt language] // Ezhegodnik finno-ugorskixh issledovanii [Yearbook of Finno-ugric Studies]. 2016. Vol. 2. Pp. 17-36. In Russian.

Krotov 1785 - Udmurtsko-russkij slovar [Udmurt-Russian dictionary] / RAN. UrO. Udmurtskij institut istorii, yazyka i literatury [RAS. UB. The Udmurt Institute of History, Language and Literature]. - Izhevsk, 1995. (= Kratkoj Votskoj slovar' s rossïjskim perevodom sobrannyj i po Alfavitu raspolozhennyj sela Elovskago Troickoj cerkvi svyashchennikom Zaharïeyu Krotovym, 1785 goda [A concise Udmurt dictionary with a Russian translation compiled and alphabetically located in the village of the Elovskogo Trinity Church by the priest Zakhar Krotov, 1785]). XX + 208 p. - (Pamyatniki kul'tury Udmurtii: Lingvisticheskoe nasledie: Pamyatniki udmurtskoj filologii I [Cultural Monuments of Udmurtia: Linguistic Heritage: Monuments of Udmurt Philology I]). In Udmurt and Russian.

Likhachev D. S. Izbrannye raboty: V 3 t. T. 1: O sebe. Razvitie russkoj literatury; Poetika drevnerusskoj literatury. Monografii [Selected works: In 3 vols. T. 1: About myself. The development of Russian literature; Poetics of Old Russian literature. Monographs]. Leningrad, 1987. In Russian.

Lytkin V. I., Teplyashina T. I. Nekotorye osobennosti glazovskogo dialekta [Some features of the Glazov dialect] // Zapiski / Udmurtskij NII ist., ekon., lit. i yazyka pri Sov. Min. Udm. ASSR. Izhevsk: Udm. kn. izd-vo Publ., 1959, vol. 19, pp. 218-227. In Russian.

Maksimov S. A. Severnoudmurtsko-komi areal'nye yazykovye paralleli: leksika, fonetika, morfolojiya [North Udmurt-Komi areal linguistic parallels: vocabulary, phonetics, morphology]. Izhevsk, 2018. 336 p. In Russian. 
Materialy - Materialy dlya sravnitel'nago slovarya zyuzdinskago permyackago i glazovskago votskago narbchij i besermenskago govora [Materials for the comparative dictionary of the Zyuzdinsk Perm and Glazovskiy narcotic narcotic and Besermensky dialects. (CGAKO) [The central state archive of the Kirov region]. Central'nyj gosudarstvenny arhiv Kirovskoj oblasti]. F. 170. Op. 1. D. 140. 32 1. In Russian.

Popova E. V. "Lakomye ohotniki do blinov... narodnaya kuhnya besermyan v istochnikah i publikaciya XIX pervoj poloviny XX stoletij» ["Delicious hunters to pancakes ... folk cuisine of the Besermyans in the sources and publication of the 19th - first half of the 20th centuries"] // Vestnik Udmurtskogo universiteta. Seriya istoriya i filologiya [Bulletin of Udmurt University. History and Philology], 2014, vol. 3. Pp. 36-45. In Russian.

Slovarj 1820 - Slovarj yazyka votskogo [Votsky language dictionary]. Nauchnyj arhiv UIIYAL UdmFIC UrO RAN. F. RF. Op. 2-N. D. 624. In Udmurt and Russian.

Sochineniya 1775 - Sochineniya prinadlezhashchiya k grammatikb votskago yazyka [Compositions belonging to the grammar of the Votsk language]. V Sanktpeterburgb pri Imperatorskoj Akademiii nauk 1775 goda [In St. Petersburg at the Imperial Academy of Sciences in 1775]. 113 p. [V kn. Pervaya nauchnaya grammatika udmurtskogo yazyka / Udm. NII ist., ekon., lit. i yazyka pri Sov. Min. Udm. ASSR. - Izhevsk: Udmurtiya Publ., 1975. - Pp. 3-15 + 113 + 17]. In Russian.

Teplyashina T. I. Yazyk besermyan [Besermyan language] // AN SSSR. In-t yazykozn. M.: Nauka Publ., 1970. 288 p. In Russian.

Teplyashina T. I. Nizhnechepeckie govory severnoudmurtskogo narechiya [The dialects of the Lower Cheptsa of the North Udmurt dialect] // Zapiski / Udmurtskij NII ist., ekon., lit. i yazyka pri Sov. Min. Udm. ASSR. Izhevsk, 1970a, vol. 21: Filology. Pp. 156-196. In Russian.

Churakov V. V. Pyotr Matveevich Sorokin - issledovatel' rodovoj organizacii udmurtov [Pyotr Matveevich Sorokin - researcher of the generic organization of the Udmurts] // Idnakar, vol. 2 (18), 2014. Pp. 153-162. In Russian.

Kel'makov V. K. Der bilabiale Sonant in den udmurtischen Dialekten // Lapponica et Uralica: 100 Jahre finnisch-ugrischer Unterricht an der Universität Uppsala: Vorträge am Jubiläumssymposium 20.-23 April 1994. Uppsala, 1996. S. 211-224. In German.

Received 18/03.2020

Ivshin Leonid Michaylovich

Candidate of Philology, Research Worker, The Udmurt Institute of History, Language and Literature, UdmFRC UB RAS 4, ul. Lomonosova, Izhevsk, 426004, Russian Federation E-mail: ivleo.75@mail.ru 